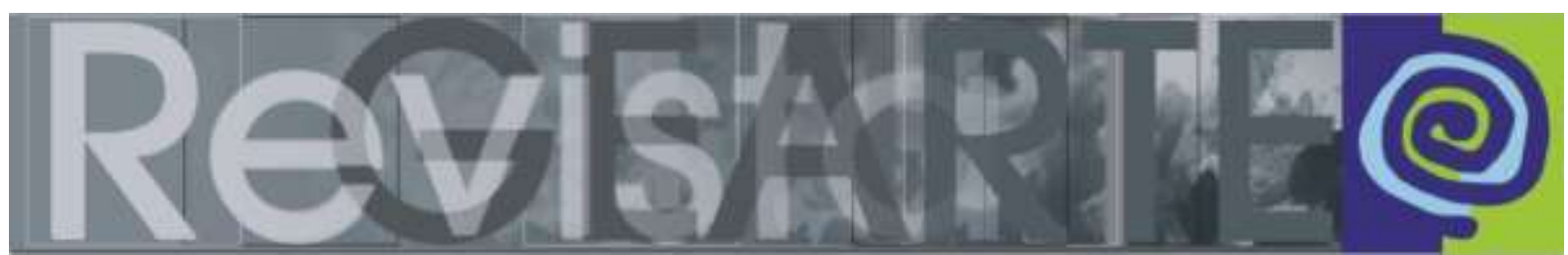

ISSN 2357-9854

\title{
O simbólico e o semi-simbólico: no entrecruzamento de duas propostas para a leitura do brasão do Papa Francisco
}

\author{
Humberto Nuno de Oliveira (ULUSÍADA - Portugal) \\ Sandra Ramalho e Oliveira (UDESC - Brasil)
}

\begin{abstract}
RESUMO
O advento da tecnologia, das comunicações virtuais e dos mecanismos de busca propiciam, além da existência de revistas científicas on-line com qualidade idêntica a das revistas impressas, igualmente as trocas acadêmicas inéditas e impensadas, como a que possibilitou a fatura deste artigo: sem se conhecerem, a não ser pelos meios virtuais, dois professores de países distintos mas de idioma único, o português, interessados por um objeto teórico comum, a leitura de imagens, mas com bases teóricas - e até mesmo, com tradições - totalmente estranhas entre si, juntam-se para um exercício teóricoanalítico. Referimo-nos à Heráldica e à Semiótica Visual. A primeira das teorias se pauta por processos simbólicos; a segunda, propõe um neologismo como conceito: a semi-simbolicidade. O que há em comum e o que é distinto, quando ambos se debruçam sobre um mesmo objeto empírico, as armas do Papa Francisco?
\end{abstract}

PALAVRAS-CHAVE

Leitura de imagem. Heráldica. Semiótica visual. Simbolismo. Semi-simbolismo.

\section{ABSTRACT}

The appearance of the technology, virtual communication and the search mechanisms have allowed beside the existence of online scientific periodics that have the same quality as the printed ones, as well as the inedited and unpremeditated academic shares such as the one that has made possible the production of this article: without knowing each other in person, beyond the virtual means, two professors from distinct countries but with the same language, the Portuguese, who are interested in the same object of study, image reading, but with theoretical bases - even traditions - totally different between them, they join to make a theoretical and analytical exercise. We are talking about the Heraldic Art and the Visual Semiotic. The first one is based on the symbolic processes; the second one establishes a neologism as a concept: the semi-symbolism. What is equal and what is distinct when both of them examine the same empirical object, the coat of arms of Pope Francis?

KEYWORDS

Image reading. Heraldic art. Visual semiotic. Symbolism. Semi-symbolism.

\section{Generalidades sobre a imagem à guisa de introdução}

Das paredes das cavernas às caves da arte tecnológica, as imagens criadas pelo homem consistem em construções discursivas, presentes em toda e qualquer sociedade, o que atesta, entre outras evidências, serem elas o resultado de uma das necessidades primárias do ser humano, qual seja, a de se expressar, tão importante quanto comer, olhar ou mover-se. Parte da cultura de cada sociedade, a imagem 
adquire características de seu tempo e lugar e serve aos mais diferentes usos, vindo ora a substituir ora a complementar as línguas naturais, verbais.

Ancestrais da escrita das línguas naturais hoje em uso e, por consequência, do próprio alfabeto ocidental, são imagens visuais, por exemplo, os pictogramas, os hieróglifos e os ideogramas. E mesmo que tendo sido condensadas e simplificadas no que se refere à forma, as letras do alfabeto atualmente utilizado no ocidente consistem em matéria-prima para a poesia visual, as artes gráficas e para a estamparia verbal, largamente utilizada na moda esportiva.

Enquanto se desenvolveram, ao longo da história, formas diversas de estruturação e expressão escrita dos sistemas linguísticos verbais, modificando-se as imagens destes sistemas até chegarem ao estágio alfabético atual, permaneceu, paralelamente, o uso das imagens como modo de representar, com características específicas, mesmo que também tenha sofrido transformações.

Verifica-se, através dos tempos, a necessidade da manutenção do uso de sistemas de imagens paralelamente aos sistemas verbais e, igualmente, de sistemas sincréticos, que são os que se utilizam do verbal, mas que funcionam dentro de uma lógica diferenciada da língua natural propriamente dita, dada a miscigenação entre o verbal e outra linguagem, desde o teatro e o cinema, até algumas manifestações da arte contemporânea e as interfaces digitais de aplicativos e de sítios na internet. Esse é também o caso da heráldica, em parte de suas manifestações, as que usam elementos visuais e verbais. Provavelmente, isso se deva ao fato de que o acervo simbólico, na mente humana, supere a capacidade de processar o conhecimento de seus significantes e significados, através do pensamento verbal. Esta premissa é defendida por Langer (1989, p. 21), quando afirma que:

[...] a mente acolhe mais do que é comumente denominado pensamento. Apenas certos produtos do cérebro fazedor de símbolos podem usar-se segundo os cânones do pensamento discursivo. Em toda a mente, existe um enorme depósito de outro material simbólico, que é aproveitado para diferentes usos ou mesmo deixado, talvez, sem uso nenhum - um mero resultado de atividade cerebral espontânea, um fundo de reserva de concepções, um excesso de riqueza mental. 
Independentemente das formas de organização visual, transformadas em decorrência das concepções de mundo, ampliadas pela capacidade imaginativa do ser humano e restritas pelos meios disponíveis - que, por sua vez, também são gradativamente diversificados pelo homem - a imagem caracteriza-se não apenas como informação, mas também como conhecimento transmissível, que se organiza em estruturas próprias.

Tanto as imagens quanto as imagens sincréticas consistem em manifestações de sistemas comunicacionais, expressas por meio de formas e cores, ou dos sistemas sincréticos, compostas por esses mesmos elementos estruturantes, juntamente com tipos gráficos, palavras, números ou letras. Servimo-nos de A. J. Greimas e J. Courtés para justificar o uso do adjetivo sincrético. No Dicionário de Semiótica, de sua autoria, afirmam "num sentido amplo, são consideradas como sincréticas as semióticas que como a ópera ou o cinema - acionam várias linguagens de manifestação" (1989, p. 426).

$\mathrm{Na}$ Heráldica encontram-se imagens pertinentes a ambos os grupos, pois existem escudos compostos somente por formas e cores, e outros por formas, cores e palavras. Para o campo teórico da semiótica discursiva, ambos os modos de manifestação, seja uma imagem estritamente visual ou uma imagem sincrética, ambos são considerados textos. Assim sendo, textos não se referem apenas à manifestações verbais, mas a unidades de sentido como um filme, uma marca, uma música. Segundo Greimas e Courtés, tanto o termo texto quanto discurso podem ser utilizados "para designar o eixo sintagmático das semióticas não-linguísticas: um ritual, um balé podem ser considerados como textos” (1989, p. 460). Daí poder-se então considerar os escudos, também, como textos.

Embora os assuntos pertinentes à heráldica remontem, ao menos, ao período medieval, o fato é que eles permanecem atuais, pois desde as grandes corporações até as unidades federativas dos Estados modernos, do país às menores realidades municipais e mesmo os times de futebol, todos querem ter as suas armas. Há até um comércio que explora famílias plebeias que buscam armas de família por meio do sobrenome seu ou de supostos ancestrais, pois consiste em um valor, uma identidade 
dignificada pela tradição e nobreza, a marca de origem, embora nem sempre comprovável.

\section{O simbólico e o semi-simbólico}

Se procurarmos no Dicionário de Semiótica de A. J. Greimas e J. Courtés (1989) o verbete símbolo, veremos que existem diversas acepções e que, ao final, os autores recomendam que não se use este vocábulo, dados os equívocos que podem surgir em virtude da polissemia que lhe é inerente, quando afirmam que "o emprego desse termo sincrético e ambíguo deve, por enquanto, ser evitado em semiótica" (1989, p. 464). Por outro lado, esses mesmos semioticistas propõem o termo semisimbólico, que vamos discutir adiante.

Antes de avançar, todavia, é necessário retomar outros dois conceitos pertencentes a esta matriz teórica, qual seja, a semiótica discursiva: plano de expressão e plano de conteúdo, que são as duas dimensões do texto, conceitos esses que substituíram e atualizaram outro binômio, postulado por Ferdinand de Saussure, qual seja, significante e significado, respectivamente. Trata-se de uma proposição de Louis Hjelmslev (1991, p. 47-79): o plano da expressão, onde elementos constitutivos ou diferenciais articulam as qualidades que um texto se utiliza para se manifestar; e o plano do conteúdo, onde a significação nasce das articulações entre estes elementos diferenciais.

Em ambos os casos, significante e plano de expressão referem-se à coisa em si, recoberta de alguma concretude, perceptível a algum dos cinco sentidos ou a mais de um, seja algo impresso em uma folha de papel, um mural, um som captado apenas pela audição, ou um aroma percebido apenas pelo olfato. E o significado ou plano de conteúdo refere-se ao campo semântico.

O que nos interessa aqui é o fato de que plano de expressão e plano de conteúdo são mais apropriados para imagens, ou textos imagéticos, sincréticos ou não, tendo em vista que sua concepção é a de uma relação de indissociabilidade entre essas duas dimensões do texto. Ou seja, a imagem pode representar, mas ela não apenas representa, pois ela é o que diz, ela fala de si, sendo mimética ou não. Quando analisamos os sistemas verbais, percebemos que, exceções feitas às onomatopeias 
em se falando de verbal oral, não há uma ligação direta entre o que a coisa é e o modo como ela é expressa, seja no verbal oral ou na sua escrita. Por exemplo, no que um substantivo despretensioso como casa, assim escrito, "c"+"a"+"s"+"a", ou este mesmo vocábulo falado, tem a ver com a residência de quem quer que seja, embora hoje tenhamos tanta diversidade no que se refere à casa? A contraprova pode se dar quando vamos a um país estrangeiro cuja língua ignoramos. Por outro lado, se tivermos uma imagem de casa, uma casa qualquer, desenhada, pintada ou fotografada por quem quer que seja, oriundo de qualquer língua e cujos costumes ignoramos, ainda conseguiremos ter uma ideia do que se trata.

Grosso modo, assim poderíamos caracterizar o simbólico, ou seja, quando não há uma relação mais estreita, ou mesmo uma coincidência, entre o plano de expressão e o plano de conteúdo; em oposição, o semi-simbólico se dá quando há. Mas vejamos outros aspectos. Nas manifestações simbólicas, os significados da palavra, imagem, som ou gesto são estabelecidos no meio social, arbitrariamente, do mesmo modo são socialmente aceitos; é necessário ser iniciado naquela linguagem, por pertencer àquele contexto social ou por aquisição por meio de memorização, como se memorizam os sinais de trânsito ou os significados do Código Morse, ou de gestos num ritual, como em uma missa católica. Os sistemas simbólicos são constituídos por normas, regras e convenções rígidas, seguidas por todos, sem o que não há comunicação; os significados são fechados e em alguns casos até herméticos; as coisas do mundo são representadas.

Em oposição, nas manifestações semi-simbólicas, há inicialmente uma simbiose entre plano de expressão e plano de conteúdo, ou seja, a expressão apresenta abertamente seu conteúdo ou, em linguagens mais complexas como a música, o plano de expressão ao menos dá pistas de seu significado. Outro aspecto é que o significado não é fechado, pois o enunciatário, ou o destinatário implícito da enunciação, é tão gerador de significados quanto o autor do enunciado, seja ele um artista visual, um compositor, um dramaturgo ou um publicitário, isto é, os significados são decididos em uma espécie de negociação entre as duas pontas do processo de comunicação. Ainda acrescente-se que é possível, nas manifestações semisimbólicas, deduzir o que cada texto quer dizer, independentemente do que seu autor 
quis dizer, e indiferentemente de que meio social vem, ou de que cânones segue. Assim sendo, no contexto de uma comunicação semi-simbólica, a significação é aberta; e as normas, regras e convenções, tão rígidas no âmbito simbólico, aqui são flexíveis e, às vezes, até objeto de transgressão em relação ao seu contexto, como no caso da arte moderna e da contemporânea. Se nas manifestações simbólicas as imagens visuais, como os emblemas e as bandeiras, ou a música, como os hinos, ou sinais, como o sinal da cruz da cristandade, a saudação nazista ou algum gestual maçônico representam grupos e ideias das mais diversas naturezas; nas manifestações semi-simbólicas as imagens visuais, músicas, gestos ou outros textos quaisquer presentificam, pois eles, mesmo estando em lugar de, constituem um novo texto, atualizado, regido por sua própria sintaxe. Um bom exemplo é nossa fotografia para documentos; ela está no nosso lugar, mas difere de nós quanto à dimensão, planaridade, pois é bi e não tridimensional, e mesmo a cor, pois malgrado o avanço da técnica, reproduzir perfeitamente as nuanças cromáticas do corpo humano, mesmo em fotografia, ainda é muito difícil. Ou seja, a foto nos presentifica, nos atualiza, nos traz para a situação presente.

\section{Texto versus leitura}

Assim caracterizadas as linguagens, poderíamos dizer que a escrita Braille, o Código Morse, os sinais de trânsito, Libras - que é a linguagem das mãos usadas pelos surdos - a Heráldica e mesmo as cartas de Tarot, podem ser consideradas linguagens simbólicas. Quanto às linguagens naturais, que são os idiomas, os estudiosos se dividem, havendo os que as consideram linguagens simbólicas e os que as consideram linguagens semióticas.

Por seu turno, as linguagens estéticas, de um modo geral, podem ser consideradas semi-simbólicas: as artes visuais, a música, o cinema. E mesmo a poesia: embora seja constituída por palavras, o processo comunicacional que a poesia propõe apresenta a mesma lógica das demais artes, pois ela fala de si mesma, ela não representa, ela é o texto mesmo que se apresenta ao enunciatário, além do que é privativo da poesia, a liberdade no uso da língua, o que chamamos de licença poética. 
Retomando o que foi colocado anteriormente, para se compreender uma manifestação de uma linguagem simbólica, ou um texto simbólico, é necessário ser iniciado naquele repertório específico. Ou seja, as mesmas normas, regras e princípios usados para construir os significados de textos simbólicos devem ser usados no processo de leitura dos mesmos textos. Por outro lado, os textos semisimbólicos são abertos e as normas e regras para construí-los são flexíveis; mas nem por isso os processos de leitura ficam entregues à mera intuição. Existem proposições metodológicas para auxiliar na condução da leitura de linguagens que não são lineares e, diferenciadamente da linguagem verbal, não se leem da esquerda para a direita e de cima para baixo, como estamos familiarizados no ocidente. Não se trata de normas rígidas, nem cânones sagrados, nem de princípios exatos. São orientações de ordem geral, a serem complementadas ou modificadas diante de cada imagem específica, tão flexíveis quanto precisam ser, uma vez que na gênese dessas manifestações estéticas e artísticas estão a liberdade de expressão, a originalidade e a projeção da singularidade de cada indivíduo criador.

Parece evidente que as regras de uma linguagem simbólica não se aplicam à leitura de textos semi-simbólicos. E o contrário, seria possível? Modelos flexíveis para o acesso aos efeitos de sentido de textos estéticos visuais, semi-simbólicos, seriam eficientes para a busca de sentidos de textos simbólicos?

Ora, se para o acesso aos conteúdos de linguagens simbólicas é necessário ser iniciados nos significados convencionados, por pertencimento ao grupo social ou por memorização, isto quer dizer que aos não iniciados esses significados ficarão para sempre inacessíveis? Bem, sabe-se que existem também as leituras intuitivas, mas essas costumam ser superficiais e mesmo equivocadas.

Assim, o que por meio deste ensaio escrito por estudiosos em duas áreas de conhecimento distintas, a Heráldica e a Semiótica Discursiva, pretende-se é mostrar duas faces de uma mesma moeda, ou dois olhares sobre um mesmo objeto, as armas do Papa Francisco, visando a atingir os seguintes propósitos: mostrar a a análise de uma mesma imagem com o uso de dois aparatos teórico-metodológicos diferentes; verificar se é possível proceder a análise de uma imagem simbólica adotando-se procedimentos usualmente adotados na leitura de imagens semi-simbólica; cotejar as 
duas análises, observando em que aspectos se aproximam e em que aspectos se distanciam, o que mesmo para os autores, a priori, foi impossível especificar.

\section{A Heráldica Eclesiástica}

Desde a Idade Média, em que a armaria se apossou do universo militar, tornando-se um código simbólico inigualável, o clero passou a fazer uso de heráldica, nascendo assim, pouco depois, a heráldica eclesiástica. No essencial, as regras gerais da heráldica, no que respeita à composição e definição do escudo, cedo porém fizeram uso, entre os ornamentos externos, de símbolos de insígnias de carácter eclesiástico e religioso, de acordo com a respectiva dignidade e jurisdição, os quais substituíam aos que entre a nobreza indicavam a sua condição guerreira ou de titulares.

É tradição, pelo menos de há oito ou nove séculos para cá, presumivelmente desde Inocêncio III - 1198-1216 (Lotário dei Conti di Segni), que também os Papas tenham passado a usar armas pessoais, para lá, evidentemente, dos demais atributos próprios da Sé Apostólica. A partir do Renascimento, tornou-se prática comum decorar com as armas do Sumo Pontífice todas as principais obras executadas durante o seu pontificado. Armas papais aparecem assim nas obras de arquitetura (tornando algumas cidades italianas verdadeiros armoriais pontifícios), em publicações, em decretos e documentos diversos e obviamente nos selos de autenticação.

Após o ritualizado processo eletivo, ocorre a escolha do nome pelo qual será conhecido o Papa, cabendo igualmente a ele a escolha das suas armas. Como bem sistematizou Miguel Metelo de Seixas (2006), os papas recorrem a três fontes de inspiração na escolha das suas armas: a adoção de armas de família, se esta as possuía, ou por vezes memórias heráldicas de pertença familiar que pretendiam assumir; a composição de armas assumidas, ditas "de devoção" ou "de fé", carregadas de simbologia religiosa que indica um propósito de vida, a referência a fatos ou experiências passadas, ou a elementos relacionados com o próprio programa de pontificado; o recurso à heráldica de função ou de instituição religiosa (uma ordem, uma diocese, uma função assumida, por exemplo). 
Não obstante estas fontes de inspiração, a escolha das armas não é totalmente nova, antes se verificando algumas variantes - cuja extensão é muito variável consoante aos pontífices - ao escudo que já haviam adotado como Bispos e que, na maioria dos casos, haviam mantido como Cardeais, apenas com a alteração dos ornamentos externos próprios da nova dignidade.

Desde os seus primórdios, para além dos elementos do escudo, escolhidos com relativa dose de liberdade, que a heráldica eclesiástica determina com apreciável rigor os ordenamentos externos que identificam o lugar na hierarquia da Igreja Católica do detentor das armas e tal vem contribuindo para que seja evidente e facilmente identificável.

Figura 1 - As armas do Papa Francisco sob o ponto de vista da Heráldica

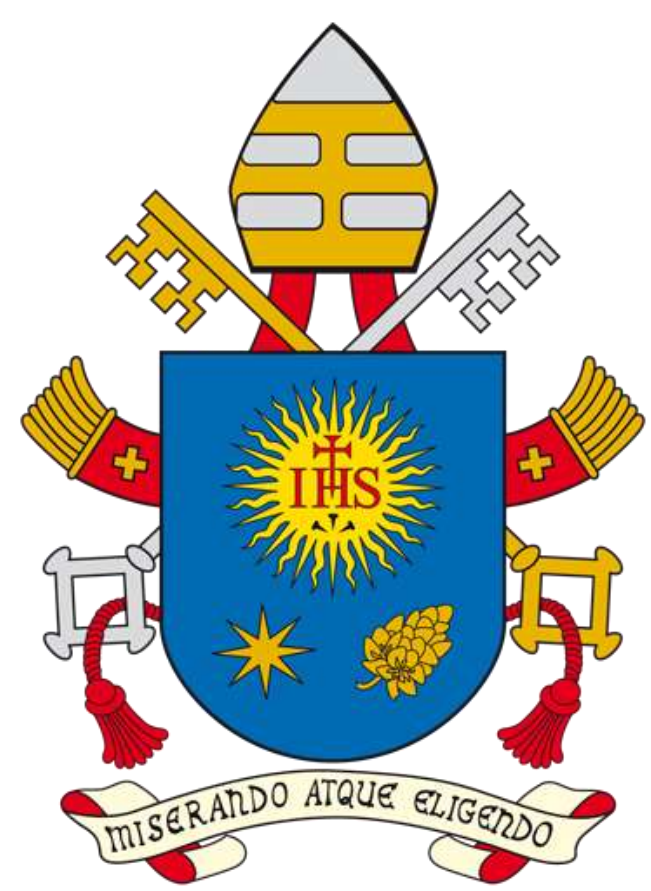

Fonte: The Coat of Arms of Pope Francis. Disponível em: $<$ http://w2.vatican.va/content/francesco/en/elezione/stemmapapa-francesco.html>.

O ornamento heráldico do atual Sumo Pontífice obedece naturalmente às regras definidas para a Heráldica Eclesiástica, com uma significativa exceção como veremos, e segue, no essencial, o modelo usado pelo seu predecessor, o atual Papa 
Emérito Bento $\mathrm{XVI}^{1}$, que abandonou a tiara pontifícia², usada na heráldica papal até o Papa João Paulo II, pontífice a cujo universo cromático o atual Papa regressou, e a substituiu pela mitra.

A mitra, possivelmente originária da Pérsia $^{3}$, tem sua origem em uma cobertura da cabeça não litúrgica e foi adotada em Roma como sinal de honra e nobreza. Deriva do camelauco (o camelaucum a partir do qual surgiu igualmente a tiara), usado antes do século $\mathrm{VIII}^{4}$, quando os papas começaram a utilizá-la, alargando-se o seu uso, entre os séculos $\mathrm{X}$ e XI, aos bispos, abades e cónegos mitrados. Desde o início do século XIV, designa-se triregnum, representando a terceira coroa a supremacia da Igreja sobre os demais Estados. Desde Paulo VI que ela não é materialmente utilizada e, mesmo então, já era usada exclusivamente fora da liturgia quando o Papa se apresentava como Chefe de Estado. Na realidade, após Paulo VI - que a usou - a tiara só foi utilizada na heráldica pontifícia além do seu uso nas armas e bandeira do Estado do Vaticano, conferindo-Ihe assim natural importância como sinal identificador de tal realidade.

Excetuando os atributos pontifícios, nos casos relativos apenas às chaves passadas em aspa ${ }^{5}$, o Papa Francisco decidiu conservar no essencial as armas anteriores de cardeal, utilizadas desde 21 de fevereiro de 2001 (e, aliás, usadas desde a sua consagração episcopal em 27 de junho de 1992), mantendo-se a nota dominante de simplicidade, que aliás vem progressivamente caracterizando a

\footnotetext{
${ }^{1}$ Bento XVI introduziu igualmente como inovação nas suas armas o pálio papal (omofório) - uma espécie de colarinho de lã branca e duas extremidades, um no peito e outro nas costas, bordado com seis cruzes, destina-se aos bispos que assumem uma arquidiocese - que foi abandonado pelo atual Papa nas suas armas, no caso do Papa simbolizando ser o pastor universal do rebanho que the foi confiado por Cristo.

${ }^{2}$ Para além do Papa apenas a um outro prelado católico é permitido o uso de uma tiara, exatamente igual, nas suas armas. Tal honrosa exceção é atributo do Patriarca de Lisboa (título criado em 1716 por instâncias do Rei D. João V) e foi tolerada desde Clemente XII, aos bispos de Lisboa que as usaram nas suas armas desde 1740 (cf. Bruno Hein 1978) até D. Manuel Gonçalves Cerejeira (1929-1971).

${ }^{3}$ Possuía originalmente uma forma cónica que é, aliás, comprovável nas moedas de Papas como Sérgio III e Bento VII que representam S. Pedro com um camelauco dessa forma.

${ }^{4}$ Como descrito na biografia do 88으 Papa Constantino (708-715), constante do Liber Pontificalis (cf. Raymond Davis 2000).

${ }^{5}$ Diz-se em heráldica quando cruzadas na diagonal, ou seja, dispostas em forma de "x".
} 
heráldica pontifícia nos últimos dois séculos e em especial no século passado. Alterou, porém, o metal dos dois móveis da ponta do seu escudo, que passaram de prata a ouro - o metal da generosidade; a estrela que passou de cinco pontas (com demasiadas conotações políticas nos tempos atuais e mesmo possíveis conotações anticristãs) ${ }^{6}$, embora seguramente escolhida por ser a denominada "estrela da epifania" ou "estrela de Belém", que assim representa o nascimento e encarnação de Jesus, para oito pontas e à flor de nardo acrescentaram-se duas pequenas folhas, para diferenciá-la de modo evidente de um simples cacho de uvas.

A descrição do seu escudo é a seguinte: escudo peninsular de azul, em chefe um sol flamejante de ouro, carregado com o monograma IHS de vermelho, sobreposta à letra "H" de uma cruz do mesmo e três cravos de negro, os dos flancos postos em faixa e o do centro em pala, sob o monograma - armas da Companhia de Jesus acompanhado em ponta de uma estrela de oito pontas, à direita, e de um ramo de flor de nardo, à esquerda, ambos de ouro.

$\mathrm{Na}$ interpretação das armas destaca-se o campo de azul, símbolo do firmamento e do manto de Maria Santíssima e, que, heraldicamente, significa usualmente: justiça, serenidade, fortaleza, boa fama e nobreza; sobre ele as armas da Companhia de Jesus, Companhia à qual pertence o pontífice (e da qual, pela primeira vez na história, um papa provém), um sol flamejante de ouro, de 32 raios retilíneos e ondulados alternadamente - o "Sol da Justiça" -, símbolo da glória, eternidade, fama, unidade e verdade, que representa Nosso Senhor Jesus Cristo, ideia reforçada pelo seu monograma: IHS (que foi o símbolo adotado pelo fundador da Ordem, o basco Santo Inácio de Loyola, em 1541)7 sobreposto o "H" pela cruz, tudo de vermelho, simbolizando o fogo da caridade inflamada no coração do Soberano

\footnotetext{
${ }^{6}$ Por um breve período foi usada a antiga estrela de cinco pontas e só depois, a Santa Sé publicou uma nova versão das armas do Papa com a alteração da estrela. Com efeito, logo após a eleição do Papa Francisco começaram a circular apreensões pelo fato do novo Pontífice usar "esse tipo de estrela".

7 Trata-se do monograma - entrelaçamento de letras iniciais - de Jesus em caracteres gregos: "iota", "eta", "sigma" = lesous. Iniciais igualmente aplicadas mais tarde, em latim, a In Hoc Signo (por este sinal), de acordo com a visão do sonho do imperador Constantino na véspera da batalha da Ponte Mílvia, no início do século IV, quando the foi dito que venceria o seu opositor pela utilização do sinal, o monograma resultante das letras gregas chi-rho, iniciais de Cristo. Igualmente em latim a expressão, lesus Hominem Salvator, Jesus Salvador dos Homens.
} 
Pontífice pelo Divino Espírito Santo, que o inspira diretamente no governo supremo da Igreja e o valor e socorro aos necessitados, que o Vigário de Cristo deve dispensar a todos os homens. Os três cravos de negro, representando essa cor a sabedoria, ciência, honestidade e firmeza, são os símbolos dos instrumentos da crucificação e da paixão que lembram a nossa redenção pelo sangue de Cristo. O Sol representa ainda a dimensão missionária da Ordem a que o Sumo Pontífice pertence.

A estrela, de acordo com a antiga tradição heráldica, simboliza a Virgem Maria, mãe de Cristo e da Igreja, sendo nessa tradição também símbolo das qualidades divinas atribuídas por Deus. Por ser de oito pontas, a denominada "estrela da redenção", associada à regeneração e ao batismo ${ }^{8}$, evoca as bem-aventuranças dos seguidores de Jesus. Na ocasião, o diretor da Sala de Imprensa do Vaticano, Padre Federico Lombardi SJ, disse que, sendo Francisco o Papa da misericórdia, alterou-se o seu número porque "as oito pontas remetem para as oito obras de misericórdia".

A flor de nardo (Polianthes tuberosa), "haste dourada" ou "vara de São José", gênero botânico muito comum na América do Sul e conhecida como muito aromática, simboliza São José - pai adotivo de Jesus e patrono da Igreja Universal, que, na tradição iconográfica da América Latina, é representado com um ramo de nardo nas mãos. Liturgicamente, é evocado a 19 de março, dia do pai em muitos países, e que é o dia em que se celebra a missa de início de pontificado de Francisco. Presente, ainda, as suas referências nos evangelhos que relatam que uma mulher ungiu os pés de Jesus com perfume de nardo, "de alto preço", o que suscitou a incompreensão de alguns presentes, para quem seria mais útil vender o bálsamo e dar o dinheiro aos pobres: "Os pobres sempre os tendes convosco, mas a mim não me tendes sempre", respondeu Jesus.

Colocando no seu escudo tais imagens, o Papa pretendeu exprimir a sua própria devoção à Nossa Senhora e ao seu marido. Somadas as três representações, obtém-se a homenagem do pontífice à Sagrada Família: Jesus, Maria e José, modelo da família humana defendido pela Igreja.

\footnotetext{
8 Por esta razão muitas pias batismais possuem esta forma. Numa ligação ao Antigo Testamento é ainda o número das pessoas salvas na Arca de Noé.
} 
Os elementos externos das armas expressam a jurisdição suprema do papa. As duas chaves passadas em aspa, uma de ouro e a outra de prata, a de ouro com o palhetão à direita, são os símbolos do poder espiritual e do poder temporal. Símbolos dos papados desde o século XIII (Inocêncio III) e passando a integrar o ordenamento heráldico no final desse século com Bonifácio VIII. São uma referência do poder máximo do sucessor de Pedro, relatado no Evangelho de São Mateus, que narra que Nosso Senhor Jesus Cristo disse a Pedro: "Tu és Pedro, e sobre esta Pedra edificarei a minha Igreja, e as portas do Abismo nada poderão contra ela. Dar-te-ei as chaves do reino dos céus, e tudo o que ligares na terra será ligado no céu, e tudo o que desligares na terra, será desligado no céu". (Mt. 16, 18-19). Por conseguinte, as chaves são o símbolo típico do poder concedido por Cristo a São Pedro e aos seus sucessores, simbologia reforçada pelo cordão que liga, ou une, as duas chaves.

A mitra pontifícia usada como timbre, absoluta inovação introduzida pelo pontífice anterior, recorda na sua forma e esmalte, a simbologia da abandonada tiara, sendo que as três faixas de ouro simbolizam os três poderes papais: Ordem, Jurisdição e Magistério, e as vertentes fundamentais da Igreja: Militante, Penitente e Triunfante, que se encontram ligadas verticalmente entre si por uma pala com suas fíbulas de vermelho ornadas com cruzes de ouro e franjadas do mesmo, indicando a sua unidade na mesma pessoa.

No listel a divisa do papa, "Miserando atque eligendo" (olhou-o com misericórdia e escolheu-o ou com misericórdia o elegeu), retirada da homilia de São Beda, o Venerável (Hom. 21; CCL 122, 149-151), o qual, comentando o episódio bíblico da vocação de São Mateus (Mt. 9, 9), escreveu: "Vidit ergo lesus publicanum et quia miserando atque eligendo vidit, ait illi Sequere me" ("Viu Jesus a um publicano e como o olhou com sentimentos de amor o elegeu e lhe disse: siga-me"). Esta homilia, reproduzida na Liturgia das Horas da Festa de São Mateus, tem um significado especial para Francisco. Em 1953, no dia litúrgico do evangelista, o jovem Jorge Mario Bergoglio experimentou, aos 17 anos, a presença de Deus na sua vida e o seu chamamento à vida religiosa, exatamente como acontecera com Santo Inácio. Uma vez nomeado bispo decidiu escolher como programa de vida a expressão "Miserando atque eligendo", tributo à misericórdia divina, que mantém agora, a par 
dos elementos que já constituíam o brasão episcopal e nortearam desde cedo o itinerário espiritual do pontífice.

Sendo a heráldica um código simbólico secular que visa o fácil reconhecimento, e não obstante reconhecer-se que o abandono da tiara se deve eventualmente ao despojamento que a heráldica eclesiástica vem progressivamente adotando relativamente aos símbolos da autoridade temporal, - uma vez que a triregnum, simboliza, na sua coroa inferior o Papa como pai de reis (a superior, a sua condição de pastor universal e a central, a igreja universal), mas não sendo a mitra exclusiva do Sumo Pontífice - a leitura e o reconhecimento das suas armas podem ser prejudicados. A tiara devia ser considerada na heráldica pontifícia como um atributo específico - independentemente da sua origem material e seu significado - tal como o são os chapéus eclesiásticos. Ao abandonar a tiara, se tal for tendência a definitiva, por que não ter criado um novo símbolo específico para o papa como sugeriu Seixas (2006)? O nosso colega e amigo não o desenhou porém, o que agora se faz após, com ele, termos confirmado a adequação do ordenamento ora proposto.

É certo que a mitra do anterior e a do atual pontífice relembram a triregnum, mas indiscutivelmente que o abandono da tiara quebra uma tradição de meio milênio e retira à heráldica pontifícia aquele que era um dos seus sinais mais identificadores.

\section{As armas do Papa Francisco sob o ponto de vista da Semiótica}

Que leitura faria um leigo em Heráldica de um texto visual construído de acordo com o rigor heráldico, ou seja, de um texto simbólico? Até que ponto a eloquência de um texto visual é autônoma? Leigo em Heráldica, mas de posse do aporte teóricometodológico que a Semiótica Discursiva oferece para a leitura de textos visuais, pode o sujeito apreender as significações propostas pelo enunciador?

Mesmo que os mais recentes desenvolvimentos da Semiótica Discursiva tenham se voltado para o estudo das situações, dos processos ou das práticas, e não mais dos textos, ainda é necessário que se continue estudando os textos, sejam eles quais forem, uma poesia, uma imagem visual, ou mesmo um vídeo postado no YouTube. E este estudo é um exemplo disto, até porque, segundo E. Landowski (2001, p. 31), 
para que práticas e textos signifiquem alguma coisa, é preciso que essas manifestações, seja qual for a sua natureza respectiva (e o observador que as leva em consideração), apresentem em si mesmas um mínimo de traços estruturais que permitam justamente que sejam "lidas".

Isso lembra que o observador não é único nem neutro e que, portanto, os sentidos depreendidos de seu encontro com o enunciado em um texto qualquer variam de acordo com suas crenças e valores, ou seja, da sua cultura. Por outro lado, as armas do Papa Francisco, que nos propusemos a analisar, apresentam, sim, traços estruturais que permitem justamente que sejam "lidas". Lancemo-nos, pois, nessa leitura.

Grosso modo, se os textos verbais são compostos por palavras (que se dividem em categorias), as quais são organizadas de acordo com normas gramaticais, os textos visuais, por seu turno, têm como elementos constitutivos pontos, linhas, planos, formas, cores, texturas e dimensões (onde cada um deles também se apresenta de modos distintos), os quais são organizados com a flexibilidade ditada por seu autor. Essa organização - ou a sintaxe do texto visual - dá-se por meio de procedimentos relacionais que articulam esses elementos constitutivos e que são buscados pelo sujeito leitor para fazer sentido.

O principal parâmetro para se perceber os procedimentos relacionais em um texto visual é o contraste. Isso porque se pode relacionar, através do contraste, duas ou mais cores, dois ou mais pontos, duas ou mais texturas, duas ou mais dimensões. Assim sendo, como acontece com respeito a todos os demais procedimentos relacionais, contraste e seu par oposto (e não antônimo), a repetição, articulam a geração de efeitos de sentido, que vão depender do que está sendo repetido ou contrastado.

O contraste e a repetição podem ser considerados referencias para a observação e análise dos mais diversos procedimentos relacionais usados na articulação de elementos constitutivos nos textos visuais. Para salientá-los, eles podem ser apresentados em duplas opostas: equilíbrio ou desequilíbrio, clareza ou ambiguidade, simetria ou assimetria, linearidade ou pictorialidade, harmonia ou desarmonia, ritmo regular ou irregular, movimento ou estaticidade, profundidade ou superficialidade, espontaneidade ou previsibilidade, estabilidade ou instabilidade, 
atividade ou monotonia, fragmentação ou unidade, exagero ou discrição, tensão ou tranquilidade, gradação ou quebra, economia ou profusão, justaposição ou independência, complexidade ou simplicidade, profusão ou concentração, ousadia ou timidez, ênfase ou anulação, naturalidade ou artificialidade, nitidez ou nebulosidade, obviedade ou sutileza, transparência ou opacidade, luminosidade ou obscuridade, continuidade ou descontinuidade, multiplicidade ou singularidade, variação ou repetição, distorção ou convenção, acaso ou planejamento, concentração ou difusão.

Este é, a princípio, um inventário de elementos constitutivos e de procedimentos relacionais que nem têm a pretensão de equivaler a uma espécie de dicionário nem a intenção de abarcar todos os elementos e procedimentos possíveis, exatamente por conta da flexibilidade da linguagem visual, que agrega novos conceitos aos seus repertórios, a cada quebra de paradigma estético de um artista contemporâneo ou decorrente de uma nova possibilidade do aparato tecnológico no que diz respeito à criação e manipulação de imagens.

Então, essa leitura proposta para o universo de imagens semi-simbólicas, aqui aplicado a uma imagem simbólica, leva em conta, inicialmente, a estrutura da imagem, sua estrutura de base: é uma vertical, uma horizontal, ou uma diagonal? São diagonais que se cruzam? É uma figura geométrica? Regular ou irregular? Após observação e considerações gerais, sem se entrar na tentativa de adivinhar o que a imagem quer dizer, parte-se para o levantamento dos elementos, após, dos procedimentos e então se inicia a atribuir significações. Esta é uma síntese do percurso, o qual já foi sobejamente explorado em inúmeras publicações.

Ao se defrontar com a imagem das armas do Papa Francisco, nesta análise, já se tem uma sugestão inevitável para a condução da atribuição de sentido a elas, que é exatamente o fato de se saber tratar-se das armas do Papa Francisco. É por esse motivo que, ao propor o estudo de imagens artísticas, recomenda-se ocultar seu título, uma vez que, sendo forte condutor do pensamento, interfere, conduz, contamina a leitura visual, pois pode resolver a questão da significação e inibe um processo mais intenso de busca de sentidos. 
Inicialmente, percebe-se que essa imagem se impõe pela sua verticalidade, pois sua dimensão vertical é superior à dimensão horizontal. Se os efeitos de sentido da horizontalidade são tranquilidade, estaticidade, repouso, mesmo uma certa conformidade e até inferioridade, de acordo com a imagem, a verticalidade alude a movimento, prontidão, alerta, sentinela, e mesmo superioridade. Deste modo, todas as imagens dessa categoria, que sempre têm a verticalidade preponderando, igualmente apresentam esses efeitos de sentido. Reitera a imponência da imagem das armas do Papa Francisco o fato de ter como estrutura básica uma linha vertical no eixo da composição, dividindo a imagem, simetricamente, em duas partes espelháveis.

A composição é formada por linhas retas, curvas e sinuosas. A paleta cromática é econômica: estão presentes as cores vermelho, azul, cinza claro (ou prata?), amarelo (ou dourado?) e preto, apenas nos contornos e nos três cravos dentro do sol.

Há duas figuras que se impõem nessa imagem, por motivos distintos. A primeira, uma forma triangular, destaca-se por sua localização, no topo da imagem e por sua forma, cujo ápice aponta para cima. A segunda figura impõe-se, por sua localização, de dois modos: por estar em primeiro plano e por estar no centro da imagem, sobre a linha imaginária que determina sua estrutura básica. Esta segunda figura destaca-se também por questões cromáticas: amarela na reprodução (ou seria dourada?), contrasta com o fundo azul. Por último, a segunda figura dominante no conjunto da imagem chama a atenção por sua forma.

Neste momento, não há como ignorar que ambas são identificáveis como figuras do mundo, dado o seu mimetismo: a primeira, a presentificação de uma mitra, o que remete diretamente para o mundo eclesiástico, uma criação originária da cultura, do mundo dos homens; a segunda, a presentificação do sol, o astro maior do nosso sistema, que leva seu nome, uma criação divina, segundo a bíblia.

O fato de que os raios de sol se intercalam, alternando raios formados por linhas sinuosas com raios formados por linhas retas geram efeitos não só de sentido, mas, antes, o efeito visual de movimento, determinado principalmente pelas sinuosas. Isso faz com que o sol pareça uma imagem que se movimenta, e pelo fato de que os raios 
são muito próximos e têm nas extremidades pontos escuros, embaralham um pouco a vista, reiterando o efeito de sentido de movimento. Não se trata de uma representação comum de sol: é um sol glorioso, um sol que se destaca, que diz: "olhem para mim", "eu estou aqui", "eu tenho algo de diferente a dizer".

No centro do sol vemos as letras IHS, com uma cruz sobre o "H"; trata-se de um símbolo, com todas as suas características: alguém iniciado nas religiões cristãs, como é o caso, sabe que significa Jesus (o "I" é o "J" em latim) Salvador dos Homens, naquela língua morta. Como estas letras são inscritas na hóstia - a presentificação do pão na celebração da missa - elas já foram traduzidas, em português como Jesus Hóstia Sagrada. A cruz sobre o "H" indica que no centro está o Filho de Deus, e seu sacrifício pelos homens está presentificado não apenas pela cruz, mas pelos três pregos logo abaixo da inscrição. Não foram três, apenas, os pregos usados na crucificação, por certo. Mas os três pregos aludem à tríade divina, Pai, Filho e Espírito Santo. Ou a Jesus, Maria e José, a Sagrada Família, ao mesmo tempo terrena e divina.

Agora se percebe que não apenas a mitra e o sol, que estão em destaque, podem ser identificáveis como objetos do mundo, mas outras figuras que compõem a imagem também: de cima para baixo, encontramos duas faixas vermelhas que saem da mitra e desaparecem por trás do escudo; duas chaves cruzadas por trás do escudo azul, deixando de fora as duas extremidades; duas pontas de estolas, iguais, assim como as chaves, sendo que nas últimas mudam apenas as cores (cinza e amarelo ou prateado e dourado?); dois cordões vermelhos com pingentes nas extremidades, formando duas linhas curvas que abraçam ou protegem o escudo; destacado do conjunto, mas quase o tocando, o que Ihe dá a conotação de pertinência está uma faixa cinza com o avesso vermelho, em forma de arco, com terminais curvos que se cruzam diagonalmente, onde se vê um lema formado por três palavras em latim.

O escudo em azul, que alude ao céu, destaca-se pela dimensão, por estar em primeiro plano, centralizado e por abrigar o sol, que com ele contrasta. Abaixo do sol dois outros elementos lhe dão sustentação compositiva: à esquerda uma estrela com oito pontas e uma espécie de cacho de uvas, mas que tem flores ao invés de bagos de uva. Os três elementos do escudo, sol, estrela e cacho de flor, são todos amarelos 
(ou dourados), conferindo-Ihes uma unidade triádica que remete à Santíssima Trindade.

A mitra, onde o amarelo/dourado parece revestir o cinza/prateado deixa vazados quatro espécies de janelas com ângulos arredondados, bem como o triângulo do ápice, este também com os ângulos da base arredondados. Essas linhas e formas, bem como as do cabo das chaves, por serem retas, passam uma ideia de síntese, de economia de formas, o que remete à noção de contemporaneidade, um conceito que distancia ou, ao menos, coloca em questão o conceito milenar das tradições católicas.

A cruz, símbolo maior do sacrifício de Cristo, está presente de vários modos, reiterando sua significação: ela está no centro do sol, em ambas as pontas das estolas à direita e à esquerda e em ambas os segredos das chaves, à direita e à esquerda. Mesmo na mitra, com seu "design contemporâneo", podemos avistar uma cruz, esta, igualmente "contemporânea".

A mitra, os segredos das chaves e as pontas das estolas apontam para 0 alto, para cima, para o céu e para o que ele representa. Mas o cabo das chaves e os pingentes das cordas apontam para baixo, para a terra e para o que ela representa, o que passa a noção de que aquela entidade diz respeito ao céu e à terra, do mesmo modo que as duas figuras centrais a mitra e o sol remetem: a primeira ao terreno, pois se trata de um artefato criado pelos homens e, o segundo, ao divino, por se tratar de uma criação, segundo a bíblia, de Deus.

Um aspecto a destacar nesta análise é que uma mesma figura ou elemento, seja ele identificável como uma coisa do mundo ou mesmo sendo uma cor ou um traço, em uma determinada linha de pensamento pode aludir a um efeito de sentido; e associado a outros elementos, gerando outra cadeia de significações, pode significar algo diferente ou até mesmo paradoxal, como é o caso da mitra: ora remete ao eclesiástico e aponta para o céu e ora se caracteriza como um conceito criado pelos homens.

Retas e curvas podem aludir à rigidez e à flexibilidade da Igreja, pois ambos os atributos são inerentes à ela: de um lado, o fiel cumprimento dos dogmas, de outros, o acolhimento dos pecadores, a compreensão acerca da imperfeição do homem, o 
perdão. A rigidez das leis está nas chaves e mesmo no escudo azul, ainda mais que neles predominam as cores frias; a transigência, o calor, a vida estão nas cordas com pingentes e nas pontas das estolas, ainda mais que são de cores quentes.

A tradição e o contemporâneo estão mesclados neste texto visual, pois o mesmo calor dos vermelhos em linhas curvas das cordas com pingentes e das pontas de estolas, assim como as figuras decorativas do escudo podem passar efeitos de sentido de barroco, de uma Igreja antiga e associada ao supérfluo, ao mesmo tempo a mitra, o desenho econômico do escudo e as chaves passam uma noção de atualidade, objetividade, despojamento.

As chaves são um segredo; segredo no início desta análise, em primeiro lugar. Em segundo, elas podem aludir às chaves de uma arca do tesouro; às chaves de uma propriedade, às chaves do coração, às chaves do reino de Deus. Enfim, chave é acesso, é desvendar, é poder abrir: chave é poder. Alude também, em se tratando de um texto visual religioso e católico, à passagem bíblica da passagens das chaves do reino de Deus a Pedro, e o Papa é o sucessor de Pedro, ele deve manter consigo e preservar as chaves desse reino. Por seu turno, as cordas, mesmo com pingentes, aludem a São Francisco, à corda que usava ao invés de cinto de couro, símbolo que permanece com os franciscanos como uma das marcas de humildade. E o nome adotado pelo Papa foi Francisco.

Comunhão com o divino e com o terreno, simultaneamente, rigidez e flexibilidade, tradição e atualidade, poder e humildade, a potencialização do céu e do divino, a presença da Trindade, o acolhimento, o despojamento, talvez até - e por que não? - o masculino (ouro, pela tradição simbólica) e o feminino (a prata, idem), são todos efeitos de sentido que um texto visual específico, o ornamento heráldico do Papa Francisco, nos oferece como fenômeno de significação, um manifesto público que deveria ser acessível, se não a toda a sociedade, ao menos aos cristãos.

A análise semiótica nunca termina, pois cada olhar sobre o objeto de estudo pode propiciar novas associações de sentido, novas correlações, novas significações. Por outro lado, a bagagem cultural, as vivências, as crenças e valores do leitor ou analista, ainda que embasado em princípios de um escopo teórico como o da 
Semiótica Discursiva, são definitivos para a apreensão de sentidos. O fato de esta análise ter sido levada a efeito por uma pessoa de formação católica certamente possibilitou percepções que não seriam possíveis a outros sujeitos, que professem outras crenças ou que sejam agnósticos ou ateus.

Entretanto, este aparato teórico-metodológico possibilita o acesso a alguns significados que um leigo em Heráldica acessaria, ateu ou católico, esses mais, aqueles menos, talvez. Fica a ideia para um novo estudo.

\section{Correlações entre o simbólico e o semi-simbólico}

As diferenças entre o simbólico, que tomaremos como sinônimo do universo heráldico, e o semi-simbólico, que usaremos como domínio da semiótica, estão, como vimos, condicionadas por uma, chamemos-Ihe metalinguística comum, a radicada numa matriz civilizacional e cultural cristã, partilhada pelos autores. Esta matriz, de modo indiscutível condiciona a percepção do representado e, nomeadamente, leva a heráldica a ter que brasonar ${ }^{9}$ de modos menos intuitivos realidades que eram percebidas corretamente numa dimensão "europeia" do fenômeno, mas que hoje se transformou mundial. A noção, numa representação heráldica, de um Agnus Dei, não será imediatamente evidente para um árabe ou um oriental.

Atendendo, assim ao que é o elemento fundamental para a heráldica, o escudo, vejamos então como se confrontam estas visões, sendo que para o semi-simbólico, desde logo, o timbre, formado pela mitra, assume papel de igual relevância.

Para tentar atingir nosso intento, estruturamos o cotejamento em três categorias, aquelas prevista por uma análise fundamentada em uma metodologia proposta pela heráldica, uma vez que para a análise pautada pela semiótica discursiva visual de matriz greimasiana, não se segmenta os elementos visuais em categorias; são inúmeros os trajetos estimulados para serem seguidos pelo olhar, inclusive são levadas em consideração arranjos de elementos que se sobrepõem, usando um ou mais elementos de outro arranjo. Em síntese, os elementos e as figuras, para a

\footnotetext{
${ }^{9}$ Dir-se-à, corretamente, do modo de ordenar e descrever os elementos constantes de um escudo de armas.
} 
semiótica, nada significam no isolamento, pois os efeitos de sentidos são resultantes das mais diversas relações entre tais elementos e figuras.

Entretanto, o método de análise heráldico é mais objetivo e foram adotadas sua terminologia e categorias para esta análise comparativa, dada a objetividade necessária para o encerramento - mas não conclusão - deste estudo. As três categorias que usamos, para organizar os dados qualitativos obtidos foram: o escudo, as cores e os elementos exteriores, conforme expostos a seguir.

Quanto ao escudo foram analisados o sol, as letras "IHS" com a cruz, os três pregos, a estrela e a flor de nardo. Para a heráldica, o sol, flamejante, é o símbolo da justiça, da glória e da eternidade; para a semiótica visual, o sol, ao ter raios, que permitem à heráldica chamá-lo de flamejante, dadas as linhas curvas desses raios, suscita o efeito de sentido de movimento e impõe-se, por sua localização, de dois modos: por estar em primeiro plano e por estar no centro da imagem, sobre a linha imaginária que determina sua estrutura básica. Esta segunda figura destaca-se também por questões cromáticas: amarela na reprodução (ou seria dourada?), contrasta com o fundo azul. O sol, astro maior do sistema solar, que leva, pois, seu nome, criação divina, segundo o Gênesis da Bíblia, é considerado por muitos como o centro do universo.

As letras "IHS" com uma cruz por trás do "H" são o símbolo da Companhia de Jesus, ordem religiosa da qual é oriundo o Papa Francisco, simbologia que a heráldica adota também para si. Para a semiótica visual, alheia ao símbolo da Companhia de Jesus, esse conjunto formado pelas letras e cruz consiste em uma referência a Jesus Cristo, por dois símbolos que, como tal, têm sua identificação por questões culturais, antes das semióticas: sendo cristão, sabe-se que a cruz cristã se refere à paixão e morte de Cristo, efeito de sentido reiterado pelos pregos logo abaixo, mais todo o conjunto sobre ou dentro do sol. Quanto às letras, a leitura igualmente não tem a ver com a semiótica propriamente, mas com o simbolismo cristão que, como todo simbolismo, é estritamente cultural.

No que diz respeito aos três pregos, para a heráldica significam o instrumento da crucificação, portanto, da paixão de Cristo; e ainda, da Sua redenção. Para a 
semiótica visual, o fato de os pregos além de reiterarem a paixão de Cristo serem três fazem uma alusão à tríade divina, Pai, Filho e Espírito Santo, pois embora a tradição cristã divulgue por meio de textos visuais e verbais que Cristo foi crucificado com o uso de pregos, é evidente que não foi apenas com três, pois não sustentariam Seu corpo, nem qualquer corpo inanimado.

Quanto à estrela, a análise com fundamentos na heráldica nos diz que ela é o Símbolo Mariano e faz alusão às obras de misericórdia. Na análise fundamentada na semiótica, a estrela compõe com o cacho de uvas e o sol, por serem da mesma cor, mas diferentes, uma reiteração da presença da trindade cristã. O cacho de uvas, para a heráldica, é a flor de nardo, a qual, visualmente, é passível de confusão com uma folha de parreira com uvas. Ela é uma referência a São José e, por extensão, à pureza.

No que se refere às cores, a heráldica analisa o azul, ouro, vermelho e negro. Para a heráldica, o azul é o firmamento, a Justiça, a serenidade, a fortaleza e a nobreza; ouro, a generosidade; o vermelho, a nobreza, o fogo da caridade e o sangue redentor de Cristo; e o negro, a sabedoria, a ciência, a honestidade e a firmeza. Se o ouro é o amarelo metalizado, o prata é o branco metalizado e na impossibilidade de usar o branco metalizado algumas vezes se usa o cinza. Há um cinza - ou prata? nas armas do Papa, cor que não foi considerada na análise.

$\mathrm{Na}$ análise com princípios da semiótica afirma-se que a paleta cromática é econômica, pois estão presentes apenas as cores vermelho, azul, cinza claro (ou prata?), amarelo (ou dourado?) e preto, apenas nos contornos e nos três cravos dentro do sol. O azul, alude ao céu e constrói o contraste que destaca os elementos amarelos ou dourados. Essas cores, assim como as demais, são analisadas pelo modelos semiótico adotado sempre em relação às formas e ao conjunto.

No que diz respeito aos elementos exteriores, o estudo heráldico considerou a mitra e as chaves. A mitra é um elemento pastoral que substitui a anterior tiara, mas que pretende manter a referência aos poderes papais e às vertentes da lgreja; as chaves, por seu turno, são o símbolo do poder espiritual e temporal e atributos do papado. Na análise semiótica, a mitra destaca-se pela localização, no alto do eixo central, bem como pelas questões cromáticas: amarelo, na reprodução (ou seria 
dourado?), remete ao outro, o metal mais preciso, que contrasta com o fundo azul. Mas a mitra, figura dominante no conjunto da imagem, chama a atenção também por sua forma.

$\mathrm{Na}$ análise com princípios semióticos, as chaves são uma figura polissêmica que remete à noções como segredo, acesso a um tesouro, à propriedade de algo material ou às chaves de um coração, às chaves do reino de Deus. Enfim, chave é acesso, é desvendar, é poder abrir: chave é poder. Alude também, em se tratando de um texto visual religioso e católico, ao trecho bíblico da passagens das chaves do reino de Deus a Pedro, e o Papa é o sucessor de Pedro; ele deve manter consigo e preservar as chaves desse reino.

Há, evidentemente, aspectos distintivos na análise destes dois domínios embora, no essencial e talvez devido à partilha da tal "metalinguística" comum, sejam detectáveis muitos pontos de encontro que não podem deixar de surpreender nesta análise comparativa.

Para além de se buscar se as significações coincidem ou não, ou qual análise é mais apropriada, cumpre mostrar como os efeitos de sentido são percebidos e reconstruídos. Talvez a maior diferença esteja posta não nos significados atribuídos às figuras, mas ao modo como são analisadas, individualmente pela heráldica e sempre em relação, pela semiótica. Assim, é possível perceber diferentes significados ao se conjugar as figuras de modos distintos, pois as articulações permitem um espectro maior de planos significantes.

Ao encerrar este primeiro relato do estudo, percebe-se que as possibilidades de leitura se abrem para o iniciado e o não iniciado em heráldica, embora se utilizado de princípios da semiótica visual, sem deixar de levar em conta que ambos os analistas têm formação religiosa cristã, partilhando de valores - imagens e figuras inerentes a essa cultura, o que determinou, independentemente de conhecimentos e métodos de um aporte teórico ou outro, por exemplo, a atribuição de sentidos às letras "IHS" com a cruz cristã por trás. 


\section{Referências}

DAVIS, Raymond (Ed.). The Book of Pontiffs (Liber Pontificalis): the ancient biographies of the first ninety Roman bishops to AD 715. 2. ed. Liverpool: University of Liverpool Press, 2000.

FERGUSON, George. Signs and symbols in Christian art. Oxford: Oxford University Press, 1966.

FONTANA, David. The secret language of symbols. Londres: Piatkus, 1997.

GREIMAS, Algirdas Julien; COURTÉS, Joseph. Dicionário de Semiótica. São Paulo: Cultrix, 1989.

HEIN, Bruno. Heraldry in the Catholic Church. Gerrards Cross: Van Duren, 1978.

HJELMSLEV, Louis. Ensaios linguísticos. São Paulo: Perspectiva, 1991.

LANDOWSKI, Eric. O olhar comprometido. Revista Galáxia, São Paulo, n. 2, p. 19-56, 2001.

LANGER, Susanne. Filosofia em nova chave. São Paulo: Perspectiva, 1989.

MONTEZEMOLO, Andrea Cordero Lanza di; POMPILI, Antonio. Manuale di Araldica ecclesiastica nella Chiesa Cattolica. Vaticano: Libreria Editrice Vaticana, 2014.

NOONAN Jr, James-Charles. The Church Visible: The ceremonial life and protocol of the Roman Catholic Church. New York: Viking-Penguin Group, 1996.

OLIVEIRA, Humberto Nuno de; SEIXAS, Miguel Metelo de. Heráldica Universitária: subsídios para o ordenamento heráldico da Universidade Lusíada. Lisboa: Universidade Lusíada Editora, 2004.

SEIXAS, Miguel Metelo de. Noticiário heráldico: as armas do Papa Bento XVI. Tabardo 3, Lisboa: Universidade Lusíada Editora, 2006.

\section{Sandra Regina Ramalho de Oliveira}

Doutora em Comunicação e Semiótica pela PUC São Paulo (1998), com pós-doutoramento na França, em Semiótica Visual (2002), é membro da ABCA (Associação Brasileira de Críticos de Arte), da AICA (Association Internationale de Critiques d'Art), da ISVS (International Association of Visual Semiotics), do CRICC (Centre de Recherche Images, Cultures et Cognitions) da Université Paris 1. Entre as publicações, é autora dos livros "Imagem também se lê" (2005;2009), "Moda também é texto" (2007); "Sentidos à mesa - saberes além dos sabores" (2010) e "Diante de uma Imagem" (2010). Foi Diretora Geral do Centro de Artes (1999-2001), Pró-Reitora de Ensino (1990-1994) e Pró-Reitora de Extensão, Cultura e Comunidade (2003), na Universidade do Estado de Santa Catarina/UDESC, onde atua desde 1987, na Graduação e, posteriormente, no Mestrado e no Doutorado em Artes Visuais, nas áreas de Semiótica Visual, Ensino de Arte e Ação Educativa em Espaços Culturais. Presidente da ANPAP/Associação Nacional de Pesquisadores em Artes Plásticas (gestão 2007-2008), foi ainda Coordenadora do Programa de Pós-Graduação em Artes Visuais (2009-2011).

E-mail: ramalho@udesc.br / ramalho@floripa.com.br

Currículo: http://lattes.cnpq.br/0870589343786662

\section{Humberto Nuno de Oliveira}

PhD em História, docente do ensino superior em Portugal desde 1985. Responsável actualmente pela área de Introdução à Heráldica no Instituto Superior de Artes Decorativas (Lisboa). Investigador do Centro Lusíada de Estudos Genealógicos, Heráldicos e Históricos da Universidade Lusíada de Lisboa e responsável na mesma instituição pelo seu departamento editorial.Presidente da Academia Falerística de Portugal e Presidente do Conselho de Fundadores da Academia Lusitana de Heráldica. Autor de dezenas de artigos e livros fundamentalmente nas áreas da Heráldica, Falerística e História Militar.

E-mail: hnlmdo@lis.ulusiada.pt

Currículo: http://lis-ulusiada.academia.edu/HumbertoNunoOliveira 